\title{
Chronic Valproic Acid Treatment Triggers Increased Neuropeptide Y Expression and Signaling in Rat Nucleus Reticularis Thalami
}

\author{
Julia Brill, ${ }^{1}$ Michelle Lee, ${ }^{1}$ Sheng Zhao, ${ }^{2}$ Russell D. Fernald, ${ }^{2}$ and John R. Huguenard ${ }^{1}$ \\ ${ }^{1}$ Department of Neurology and Neurological Sciences, Stanford University School of Medicine, and ${ }^{2}$ Department of Biological Sciences, Stanford University, \\ Stanford, California 94305
}

\begin{abstract}
Valproate (VPA) can suppress absence and other seizures, but its precise mechanisms of action are not completely understood. We investigated whether VPA influences the expression of neuropeptide Y (NPY), an endogenous anticonvulsant. Chronic VPA administration to young rats $\left(300-600 \mathrm{mg} \cdot \mathrm{kg}^{-1} \cdot \mathrm{d}^{-1}\right.$ in divided doses over $\left.4 \mathrm{~d}\right)$ resulted in a $30-50 \%$ increase in NPY mRNA and protein expression in the nucleus reticularis thalami (nRt) and hippocampus, but not in the neocortex, as shown by real-time PCR, radioimmunoassay, and immunohistochemistry. No increased expression was observed after a single acute dose of VPA. Chronic treatment with the pharmacologically inactive VPA analog octanoic acid did not elicit changes in NPY expression. No significant expression changes could be shown for the mRNAs of the $\mathrm{Y}_{1}$ receptor or of the neuropeptides somatostatin, vasoactive intestinal polypeptide, and choleocystokinin. Fewer synchronous spontaneous epileptiform oscillations were recorded in thalamic slices from VPA-treated animals, and oscillation duration as well as the period of spontaneous and evoked oscillations were decreased. Application of the $\mathrm{Y}_{1}$ receptor inhibitor N2(diphenylacetyl)- $N$-[(4-hydroxyphenyl)methyl]-D-arginine-amide (BIBP3226) enhanced thalamic oscillations, indicating that NPY is released during those oscillations and acts to downregulate oscillatory strength. Chronic VPA treatment significantly potentiated the effect of BIBP3226 on oscillation duration but not on oscillation period. These results demonstrate a novel mechanism for the antiepileptic actions of chronic VPA therapy.
\end{abstract}

Key words: epilepsy; absence seizures; spike-wave discharges; nRt; hippocampus; thalamus

\section{Introduction}

Neuropeptide Y (NPY), the most abundant neuropeptide in the CNS, is expressed in a subset of hippocampal and cortical interneurons as well as virtually all neurons of the nucleus reticularis thalami (nRt). It exerts diverse effects [e.g., on feeding (Erickson et al., 1996), neuronal proliferation (Hansel et al., 2001), and angiogenesis (Ekstrand et al., 2003)] and is a putative endogenous anticonvulsant (Vezzani et al., 1999; Vezzani and Sperk, 2004). Results from several studies suggest that NPY regulation is an important modulator of epilepsy and epileptogenesis. NPY upregulation in various brain regions was found in response to kindling (Marksteiner et al., 1990), and NPY delayed kindling progression in the hippocampus (HC) (Reibel et al., 2000). Increased NPY expression occurs in hippocampal mossy fibers in the pilocarpine model of epileptogenesis (Tu et al., 2005). NPY

Received Sept. 27, 2005; revised May 9, 2006; accepted May 18, 2006.

This work was supported by National Institute of Neurological Disorders and Stroke Grant NSO6477 (J.R.H.) and J. Javits Award NS34950 (R.D.F.). We thank Isabel Parada for expert assistance and advice with immunostaining and Gunnar Kwakye for technical assistance.

Correspondence should be addressed to Dr. John R. Huguenard, Department of Neurology and Neurological Sciences, Stanford University School of Medicine, 300 Pasteur Drive, Room M016, Stanford, CA 94305. E-mail: john.huguenard@stanford.edu.

DOI:10.1523/JNEUROSCI.5320-05.2006

Copyright $\odot 2006$ Society for Neuroscience $\quad$ 0270-6474/06/266813-10\$15.00/0 knock-out mice have a decreased seizure threshold and exhibit occasional spontaneous seizures (Erickson et al., 1996).

NPY is a ligand for a family of six G-protein-coupled receptors $\left(\mathrm{Y}_{1}-\mathrm{Y}_{6}\right)$. In the thalamus, a forebrain region centrally involved in the generation of typical absence seizures (Meeren et al., 2002), $\mathrm{Y}_{1}$ receptors mediate activation of inwardly rectifying potassium channels, whereas $\mathrm{Y}_{2}$ receptor activation inhibits high-voltagegated calcium channels and thus neurotransmitter release (Sun et al., 2001a,b). In rodent slices, stimulus trains delivered to the afferent fibers in the internal capsule activate nRt neurons, triggering NPY release and activation of $Y_{1}$ receptors. The resulting long-lasting hyperpolarization of nRt cells is a potentially antiepileptic effect (Sun et al., 2003b).

Valproate (VPA) is used in the treatment of absence and other seizures (Löscher, 1999); however, its exact mechanism of action is not fully understood. VPA exerts profound effects on gene transcription, through inhibition of histone deacetylase (Phiel et al., 2001) and activation of transcription factors and signaling cascades (Asghari et al., 1998; Chen et al., 1999; Einat et al., 2003; Ren et al., 2004; Hao et al., 2004). In addition, it has been shown to have direct effects on GABA (Eckstein-Ludwig et al., 1999; Fraser et al., 1999; Whitlow et al., 2003) and glutamate (Ueda and Willmore, 2000; Hassel et al., 2001; Morland et al., 2004) transporters. However, there is little general consensus on the qualitative and quantitative characteristics of these effects. Clinical data 
Table 1. PCR primers in $5^{\prime}-3^{\prime}$ direction

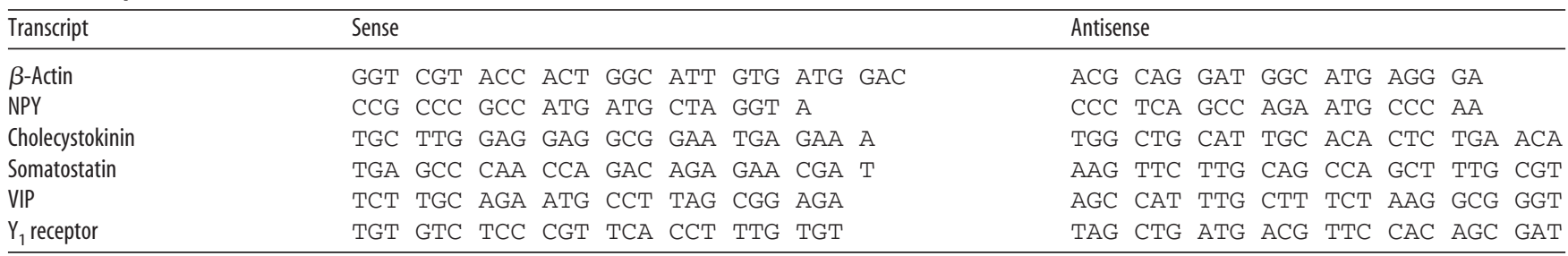

suggest that VPA has both immediate and longer-lasting effects: although it effectively treats status epilepticus (Sirven and Waterhouse, 2003), there is poor correlation between plasma levels and clinical efficacy (Burr et al., 1984; Chadwick, 1985; Sundqvist et al., 1998), effective seizure control may only be achieved after days or weeks of treatment (Henriksen and Johannessen, 1982; Bourgeois et al., 1987), and effects may persist after cessation of treatment (Rowan et al., 1979).

Preliminary data from hippocampal cultures suggest that VPA treatment can alter NPY expression (Nadi et al., 1999). Here, we tested whether chronic VPA administration influences NPY expression and signaling in rat CNS, especially in thalamus, and whether this might be at least in part responsible for its chronic antiepileptic effects.

\section{Materials and Methods}

Animals. All experiments were performed according to protocols approved by the Stanford Institutional Animal Care and Use Committee. For chronic treatments, Sprague Dawley rats aged postnatal day 20 (P20) and older at the end of the trial were injected intraperitoneally every $8 \mathrm{~h}$ for up to $4 \mathrm{~d}$ with $200 \mathrm{mg} / \mathrm{kg}$ sodium valproate (VPA), the pharmacologically inactive analog sodium octanoate (OA) (Löscher and Nau, 1985), $67 \mathrm{mg} / \mathrm{ml}$ diluted in water (Löscher and Honack, 1995), or the same volume of saline. Younger rats (P14 and P15 at the end of the trial) were injected subcutaneously with $50 \mathrm{mg} / \mathrm{kg} \mathrm{VPA}$ or OA on the first day, 100 $\mathrm{mg} / \mathrm{kg}$ on the second, and $200 \mathrm{mg} / \mathrm{kg}$ on subsequent days. Higher initial doses were found to cause sedation and failure to feed, similar to clinical symptoms of acute VPA overdose (Eyer et al., 2005). The dosages administered have been shown to result in serum VPA levels similar to those seen in patients receiving VPA treatment (Löscher and Honack, 1995).

Slice/tissue preparation. Rats (P13-P15 for electrophysiology; P14P24 for RNA and peptide extraction) were anesthetized with $50 \mathrm{mg} / \mathrm{kg}$ sodium pentobarbital and decapitated $\sim 2-4 \mathrm{~h}$ after the last injection. Brains were immediately transferred into cold sucrose solution containing the following (in mM): 234 sucrose, 11 glucose, $24 \mathrm{NaHCO}_{3}, 2.5 \mathrm{KCl}$, $1.25 \mathrm{NaH}_{2} \mathrm{PO}_{4}, 2 \mathrm{MgSO}_{4}$, and $0.5 \mathrm{CaCl}_{2}$, equilibrated with a $95-5 \%$ mixture of $\mathrm{O}_{2}$ and $\mathrm{CO}_{2}$. Horizontal slices $(400 \mu \mathrm{m})$ were cut on a VT $1000 \mathrm{~S}$ Vibratome (Leica, Bensheim, Germany) at $4^{\circ} \mathrm{C}$ in sucrose solution. For electrophysiological recordings, slices were trimmed to exclude hippocampus and cortex and incubated in a holding chamber filled with artificial CSF (ACSF) (in ms: $126 \mathrm{NaCl}, 26 \mathrm{NaHCO}_{3}, 2.5 \mathrm{KCl}, 1.25$ $\mathrm{NaH}_{3} \mathrm{PO}_{4}, 2 \mathrm{CaCl}_{2}, 2 \mathrm{MgCl}_{2}, 10$ glucose, equilibrated with $95 \% \mathrm{O}_{2} / 5 \%$ $\mathrm{CO}_{2}, \mathrm{pH} 7.4$ ) at $32^{\circ} \mathrm{C}$ for $1 \mathrm{~h}$ and subsequently in the same solution at room temperature. For RNA and peptide extraction, nRt, neocortex, and hippocampus were microdissected from $400 \mu \mathrm{m}$ horizontal slices and immediately immersed in Trizol solution (for RNA extraction) or flash frozen in liquid nitrogen (for peptide extraction) and stored at $-70^{\circ} \mathrm{C}$.

Quantitative RT-PCR ( $q R T-P C R)$. Microdissected tissue was placed in $1 \mathrm{ml}$ of Trizol (Invitrogen, San Diego, CA). Addition of $250 \mu \mathrm{l}$ of chloroform (Sigma, St. Louis, MO) was followed by centrifugation and collection of the upper, aqueous phase containing the RNA. Total RNA was precipitated by adding $500 \mu \mathrm{l}$ of isopropanol followed by a $75 \%$ ethanol wash and air-drying. One microgram of total RNA was reverse transcribed using the iScript cDNA Synthesis kit (Bio-Rad, Hercules, CA). Primers used in this study are listed in Table 1. qRT-PCR was performed using $30 \mu \mathrm{l}$ triplicate reactions with $1 \times$ IQ SYBR Green Supermix (Bio-
Rad), $0.5 \mu \mathrm{M}$ each primer, and $0.5 \mathrm{ng} / \mu \mathrm{l} \mathrm{cDNA}$ (RNA equivalent) for each tissue sample and each gene on the MyIQ Single-Color Real-Time PCR Detection System (Bio-Rad). PCR parameters were as follows: 5 min at $95^{\circ} \mathrm{C}, 45$ cycles of $30 \mathrm{~s}$ at $95^{\circ} \mathrm{C}, 30 \mathrm{~s}$ at $60^{\circ} \mathrm{C}$, and $30 \mathrm{~s}$ at $72^{\circ} \mathrm{C}$, followed by melt curve analysis. We detected fluorescence at $490 \mathrm{~nm}$ at the start of the annealing step $\left(60^{\circ} \mathrm{C}\right)$ in each cycle. The raw, backgroundsubtracted fluorescence data provided in the MyIQ software were analyzed by the real-time PCR Miner program (Zhao and Fernald, 2005). The resulting PCR efficiency and fractional cycle number of the threshold $\left(C_{\mathrm{T}}\right)$ were used for transcript quantification. mRNA expression was normalized to $\beta$-actin mRNA.

Radioimmunoassay. For peptide extraction, microdissected tissue was resuspended in $0.5 \mathrm{M}$ acetic acid, homogenized using a Polytron tissue homogenizer and boiled for 10-15 min (Kraiczi et al., 1997). Debris was pelleted by centrifugation at $5000 \times g$ for $10 \mathrm{~min}$ at $4^{\circ} \mathrm{C}$, and the supernatants were vacuum dried and resuspended in 200-500 $\mu$ l of radioimmunoassay buffer (Peninsula Laboratories, Belmont, CA). Total protein content was determined in triplicate for each sample (BCA protein assay kit; Pierce, Rockford, IL). Radioimmunoassays were performed using a commercial kit (Bachem, Torrance, CA). Briefly, samples were analyzed using $150 \mu \mathrm{g}$ of protein each and quantified in duplicate or triplicate according to a standard curve using known NPY concentrations (1-128 $\mathrm{pg} /$ reaction). Controls and samples were incubated overnight at $4^{\circ} \mathrm{C}$ in a rabbit polyclonal NPY antibody solution. After addition of ${ }^{125}$ I-labeled NPY, samples and standards were incubated overnight at $4^{\circ} \mathrm{C}$. Goat-antirabbit IgG serum and normal rabbit serum were added to precipitate antibody-bound complexes at room temperature, which were then pelleted by centrifugation at $1700 \times g$ for $20 \mathrm{~min}$ at $4^{\circ} \mathrm{C}$. Supernatants were discarded and the radioactive counts determined in a gamma counter (Gamma4000; BioNiQuest, Concord, CA).

Immunohistochemistry. Rats were deeply anesthetized with $50 \mathrm{mg} / \mathrm{kg}$ sodium pentobarbital and transcardially perfused with $100 \mathrm{ml}$ of saline, followed by $300 \mathrm{ml}$ of $4 \%$ paraformaldehyde in $0.1 \mathrm{M}$ phosphate buffer. Brains were removed and postfixed overnight at $4^{\circ} \mathrm{C}$, cryoprotected in $30 \%$ sucrose for $2-3 \mathrm{~d}$ at $4^{\circ} \mathrm{C}$, frozen, and sectioned at $40 \mu \mathrm{m}$ on a cryotome (HM 400; Microm, Heidelberg, Germany). Sections were stored in PBS, pH 7.4 at $4^{\circ} \mathrm{C}$ for a maximum of $14 \mathrm{~d}$. Sections were processed in a manner similar to the protocol described previously (Sun et al., 2003b). Free-floating sections were rinsed in $75 \%$ ethanol and PBS and then blocked in $10 \%$ normal goat serum/PBS for $2 \mathrm{~h}$. Subsequently, they were incubated on a rotary shaker for $16 \mathrm{~h}$ at $4^{\circ} \mathrm{C}$ in a mixture of rabbit polyclonal NPY antiserum (1:1000 dilution; Sigma) and monoclonal mouse NeuN antibodies (1:1000 dilution; Chemicon, Temecula, CA) in PBS and $0.2 \%$ Triton X-100. After rinsing in PBS, sections were incubated on a rotary shaker at room temperature with fluorescence-labeled goat anti-rabbit (Alexa Fluor 488; $2 \mu \mathrm{g} / \mathrm{ml}$; Invitrogen) and goat antimouse IgG (Alexa Fluor 568; $2 \mu \mathrm{g} / \mathrm{ml}$; Invitrogen) for $1 \mathrm{~h}$. Sections were mounted on SuperfrostPlus slides (Fisher Scientific, Houston, TX) and coverslipped using Vectashield mounting medium (Vector Laboratories, Burlingame, CA). Double immunofluorescence was assessed by confocal microscopy (LSM 510 Confocal Laser Scanning Microscope; Zeiss, Oberkochen, Germany). Red (NeuN/Alexa Fluor 568; excitation wavelength, $543 \mathrm{~nm}$; emission analyzed for $\lambda>560 \mathrm{~nm}$ ) and green (NPY/ Alexa Fluor 488; excitation wavelength, $488 \mathrm{~nm}$; emission analyzed at $\lambda=500-530 \mathrm{~nm}$ ) immunofluorescence channels were imaged. For each paired trial, matched images were compared semiquantitatively, and identical image acquisition settings were chosen such that pixel intensi- 
ties in each channel were not saturated. Brains of VPA- and OA-treated littermates in each trial were processed strictly in parallel during all steps involved in fixing, sectioning, and staining, and the investigators processing the sections and analyzing the data were blinded to the treatment of the animals. Images $(20 \times)$ from two to six sections per animal and brain region were analyzed using SigmaScan Pro5 software. Red immunofluorescence $(\mathrm{NeuN})$ demarcated the area of each neuronal soma. Because NeuN expression was unaltered by the various treatments, we selected the area to be analyzed based on clearly visible somata. In nRt, where NPY expression was mainly somatic, red and green pixel intensities were recorded for these areas and the average green (NPY) pixel intensity was normalized to the average red (NeuN) pixel intensity for each clearly outlined soma. We then averaged individual green/red ratios for each section and each animal. To quantify NPY immunofluorescence in paraventricular nucleus of the hypothalamus (PVN), paraventricular nucleus of the thalamus (PVT), cortex, and dentate gyrus (areas expressing NPY mainly in processes) we calculated average green pixel intensities in demarcated areas and normalized the values to the average red pixel intensities in somata contained within these areas. To demarcate processes, we set a threshold at $2 \times$ nonspecific background as measured in a visually identified area that did not contain specific NPY or NeuN immunofluorescence.

Extracellular recordings. Extracellular thalamic recordings were performed as described previously (Huguenard and Prince, 1994; Sun et al., $2002,2003 b)$. Briefly, slices were transferred into an interface recording chamber and superfused with modified ACSF solution containing $1 \mathrm{~mm}$ $\mathrm{MgCl}_{2}, 20 \mu \mathrm{M}$ bicuculline methiodide, and $500 \mu \mathrm{M}$ L-glutamine. Extracellular multiple-unit activities in nRt were recorded using monopolar tungsten electrodes (0.2-2 M $\Omega$; Frederick Haer, Bowdoinham, ME) and a Grass amplifier (bandwidth, $0.03-3 \mathrm{kHz}$ ). All data were digitized (10 $\mathrm{kHz}$ ) and stored using pClamp software (Molecular Devices, Palo Alto, CA). Single extracellular stimuli $(40 \mu \mathrm{s})$ were delivered to the internal capsule at intervals between 20 and $60 \mathrm{~s}$ through a bipolar sharpened tungsten electrode. Typically, 10 sweeps were recorded in control solution (ACSF), 10 sweeps in ACSF with the test substance at the indicated concentrations, and the remaining 16 sweeps in ACSF (washout). The first four ACSF sweeps, as well as the first two test substance and washout sweeps were excluded from data analysis. When comparing slices from OA- to VPA-treated animals, slices were prepared in parallel and recordings were made in an alternating pattern. To quantify the degree of synchrony and the duration of the ensuing thalamic oscillations, autocorrelograms were constructed from the spike times obtained from extracellular recordings. Distinct autocorrelogram components were measured using a modified Gabor function: $y=A_{\mathrm{O}}\left(e^{-t / \tau \mathrm{o}}\right)^{1.5}(\cos (t \pi /$ p) $)^{6}+A_{\mathrm{R}} e^{-t / \tau_{\mathrm{R}}}$, where $A_{\mathrm{O}}$ and $A_{\mathrm{R}}$ are the amplitudes and $\tau_{\mathrm{O}}$ and $\tau_{\mathrm{R}}$ the decay constants of the oscillatory and nonoscillatory components, respectively; $p$ is the period of the oscillatory component; and $t$ is time (Cox et al., 1997). We rejected recordings in which $\tau_{\mathrm{O}}$ during drug washout was not within $75-133 \%$ of control (ACSF) conditions or in which the coefficient of variation for $\tau_{\mathrm{O}}$ exceeded $5 \%$.

Reagents and concentrations. Reagents and concentrations were as follows: N2-(diphenylacetyl)- $N$-[(4-hydroxyphenyl)methyl]-D-arginineamide (BIBP3226) (Bachem; $1 \mu \mathrm{M}$ ); sodium valproate [Sigma; 67 $\mathrm{mg} / \mathrm{ml}$ (403 mM)]; sodium octanoate [Sigma; $67 \mathrm{mg} / \mathrm{ml}(403 \mathrm{~mm})$ ]; bicuculline methiodide (Sigma; $20 \mu \mathrm{M}$ ); and neuropeptide FF (NPFF) (Bachem; $2 \mu \mathrm{M}$ ).

Statistics. Error bars represent SEMs. We tested for statistical significance using an unpaired $t$ test except for the data in Figure 2 (radioimmunoassay) in which a two-way ANOVA followed by Bonferroni's post test was used. We used normalized data to analyze amplitude and duration of thalamic oscillations under various conditions, because these parameters were highly variable between slices and there was no significant correlation between either oscillation decay constant or amplitude under control conditions and the extent of change associated with BIBP3226 treatment (data not shown).

\section{Results}

In this study, we assessed the influence of chronic VPA treatment on the expression and signaling of NPY.

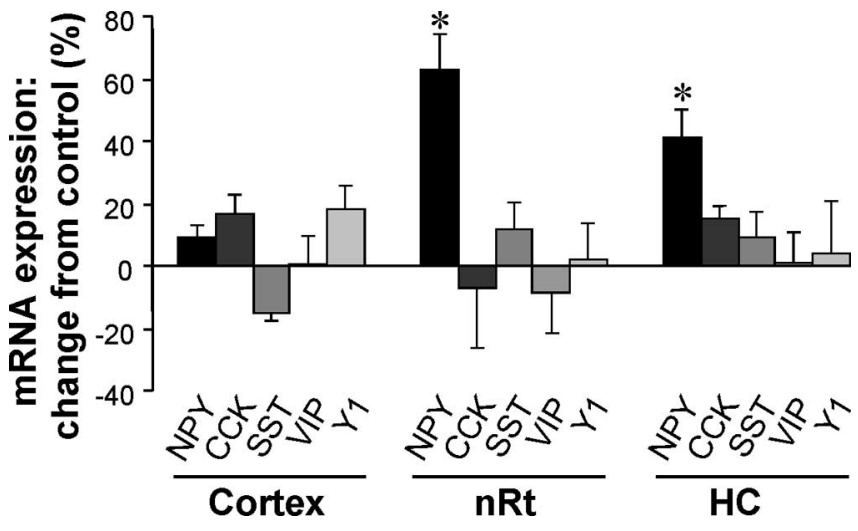

Figure 1. qRT-PCR: increased NPY mRNA expression. mRNA for NPY, CCK, SST, VIP, and $Y_{1}$ receptor ( $\mathrm{Y} 1$ ) was quantified in cortex, $\mathrm{nRt}$, and $\mathrm{HC}$ from six animals ( $\mathrm{HC}, 5$ animals), aged $\mathrm{P} 20$, treated with VPA or OA for $4 \mathrm{~d}$. Expression changes in percentage compared with six control littermates treated with $\mathrm{OA}$ for $4 \mathrm{~d}$ are shown. The asterisks denote values that significantly differ from control $(p<0.05)$. NPY mRNA expression was significantly increased in nRt and hippocampus of chronically VPA-treated animals. Error bars indicate SEM.

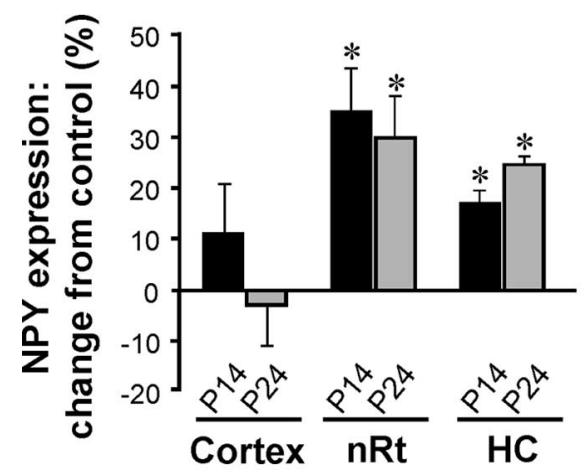

Figure 2. Radioimmunoassay: increased NPY protein expression. NPY was quantified in cortex, nRt, and HC from animals aged P14 (light gray bars; $n=4$ ) and P24 (dark gray bars; $n=$ 4) treated with VPA for $4 \mathrm{~d}$. Bars represent percentage change from $4 \mathrm{~d} 0 \mathrm{~A}$-treated animals $(n=$ 4 in each age group). NPY protein expression is significantly increased in $n R t$ and hippocampus but not cortex of chronically VPA-treated P14 and P24 animals. Error bars indicate SEM.

\section{Chronic VPA treatment increases NPY mRNA expression}

For quantification of NPY transcript levels, we microdissected nRt, hippocampus, and neocortex of P20 rats chronically treated with VPA or OA, and an investigator blinded to the treatment of the animals performed RNA extraction, reverse transcription, and quantitative PCR analysis. Chronic VPA treatment was associated with a significant increase in NPY mRNA in $\mathrm{nRt}(+62.7 \pm$ $11.5 \% ; n=6 ; p<0.01)$ and hippocampus $(+41.1 \pm 9.0 \% ; n=5$; $p<0.005)$, but not in cortex $(+9.1 \pm 4.1 \% ; n=6 ; p>0.1)$, whereas no significant changes were observed for transcripts of three other neuropeptides expressed in thalamus, cholecystokinin (CCK), somatostatin (SST), and vasoactive intestinal polypeptide (VIP) or for $\mathrm{Y}_{1}$ receptor mRNA (Fig. 1).

Chronic VPA treatment results in elevated NPY protein levels To assess whether there was a comparable expression change for the protein product as well, NPY levels in cortex, hippocampus, and nRt were quantified using a radioimmunoassay. Rats used in these experiments were likewise chronically treated with VPA or OA for $4 \mathrm{~d}$ ( $n=4$ each). Results for rats aged P24 were consistent with mRNA analysis (Fig. 2), showing significant increase in NPY protein in $\mathrm{nRt}(+30.4 \pm 8.4 \% ; p<0.05)$ and in hippocampus $(+24.9 \pm 1.7 \% ; p<0.05)$, whereas cortical NPY levels were not 
significantly altered $(-2.8 \pm 8.4 \%)$ compared with controls. P14 animals were chronically treated with 50 or $100 \mathrm{mg} / \mathrm{kg} \mathrm{VPA}$ or OA (data summarized), and we found a trend similar to what we had observed in the older animals: no significant alterations in NPY levels in cortex $(+11.6 \pm 9.1 \%)$, but significant increases in $\mathrm{nRt}(+35.7 \pm 8.2 \% ; p<0.05)$ and hippocampus $(+17.4 \pm 2.4 \%$; $p<0.05)$.

To address NPY expression within tissues of interest, we performed semiquantitative fluorescent immunohistochemical costainings using antibodies against NPY and NeuN, a neuronal marker protein that was used to localize neuronal somata and normalize NPY immunofluorescence. Figure 3 shows representative overview images of a number of brain regions in coronal sections from chronically OA- (Fig. $3 A 1, B 1, C 1, D 1, E 1$ ) and VPA(Fig. $3 A 2, B 2, C 2, D 2, E 2)$ treated P24 littermates. The brain regions examined were nRt (Fig. 3A1,A2), the dentate gyrus (HC) (Fig. 3B1,B2), middle layers of the primary somatosensory cortex (CX) (Fig. 3C1,C2), the PVT (Fig. 3D1,D2), and the PVN (Fig. $3 E 1, E 2)$. The latter two brain regions contain dense dendritic processes expressing high levels of NPY (Chronwall et al., 1985; Tabb et al., 2004). NeuN immunofluorescence, shown in red, was detected in nuclei and cell bodies and its intensity did not vary significantly between tissue from OA- and VPA-treated animals. Green immunofluorescence, corresponding to NPY, was found in cell bodies as well as processes. In the nRt, NPY colocalized with virtually all NeuN-expressing cells (i.e., all presumptive neurons), whereas no NPY immunofluorescence was found in cell bodies of thalamocortical relay neurons in the neighboring ventrobasal nucleus of the thalamus (VB) (line indicating border with nRt).

Quantification of the intensities for NPY-specific immunofluorescence, normalized to NeuN-specific immunofluorescence in nRt, dentate gyrus, cortex, PVT, and PVN of VPA- and OAtreated animals revealed higher NPY/NeuN ratios with chronic VPA treatment in nRt and dentate gyrus but not in the other regions examined (Table 2) (two to six sections each from six animals, each aged P14, and four animals, each aged P24). In nRt, where virtually all neurons express NPY, we quantified NPY and NeuN immunofluorescence within cell bodies. In the other regions, NPY-expressing neurons were sparse and immunoreactivity mainly localized to processes where there was no NeuN staining. We therefore quantified NPY immunoreactivity in processes and by normalizing it to NeuN immunoreactivity in cell bodies in the immediate vicinity of the NPY-positive processes in the same image. In the dentate gyrus, we observed increased NPY expression both in hilar NPY-expressing interneurons and in molecular layer fibers (Fig. 3, compare B1, B2).

Figure 4 shows detailed images of thalamus of chronically OA$(A 1-A 3)$ or VPA- $(B 1-B 3)$ treated animals. The elevated NPY expression is evident in cell bodies of nRt neurons as well as in fibers (Fig. 4 B2, arrowheads) and in diffuse gray matter staining (Fig. 4, compare A2, B2). In the merged NPY (green) and NeuN (red) images, the elevated somatic NPY expression causes cell bodies of nRt neurons to look yellow (Fig. 4A3,B3). No equivalent intensity differences were observed for the control protein, NeuN (Fig. 4, compare A1,B1).

\section{Effect of VPA on thalamic oscillations and NPY signaling}

To determine whether the upregulation of NPY mRNA and protein results in increased amounts of mature, releasable NPY, we studied oscillations in thalamic slices from young rats. Pharmacological studies in this system have provided evidence for NPY release and subsequent physiological modulation of oscillatory network activity (Sun et al., 2003b), and provide an experimental model in which to quantify physiological effects of NPY signaling within the nRt.

\section{Chronic VPA treatment affects spontaneous oscillations}

Before investigating the impact of VPA-mediated NPY upregulation, we determined the effects of chronic and acute VPA treatment on thalamic oscillations, because VPA may also affect neuronal excitability in the thalamus through mechanisms independent of NPY. In $20 \mu \mathrm{m}$ bicuculline methiodide and $1 \mathrm{~mm}$ $\mathrm{Mg}^{2+}$, thalamic slices will oscillate spontaneously (Jacobsen et al., 2001). We recorded spontaneous thalamic oscillations under these conditions using two recording electrodes within the nRt, spaced $\sim 0.5 \mathrm{~mm}$ apart. Several differences in spontaneous activity were found in slices from chronically VPA-treated animals compared with OA controls (VPA, nine slices from four animals; OA, six slices from three animals). First, slices from VPA-treated animals oscillated with a higher intrinsic frequency (Fig. 5A1); the average period being $366 \pm 14(2.7 \mathrm{~Hz}) \mathrm{ms}$ compared with $423 \pm 13 \mathrm{~ms}(2.4 \mathrm{~Hz})$ in controls $(p<0.05)$ (Fig. 5A2). Second, oscillation asynchrony (i.e., the amount of time oscillations were recorded in only one of the closely spaced electrodes) was elevated with VPA treatment. Figure 5B1 shows representative simultaneously recorded traces from a VPA-treated animal. Oscillations were either absent on both electrodes (indicated by gray central line), recorded simultaneously (synchronously) on both electrodes (black line), or recorded on only one electrode (black dotted line). The last includes cases in which either an entire oscillation was detected with only one electrode or oscillations began or ended asynchronously. Expressing the time during which oscillations were recorded with only one electrode as a fraction of the total time oscillations were recorded on either electrode (Fig. 5B2), we found that this "oscillation asynchrony" was significantly higher with VPA treatment (OA, $5.1 \pm 1.3 \%$; VPA, $20.4 \pm 4.5 \%$; $p<0.05)$. Third, we measured the mean duration of spontaneous oscillations within the first $250 \mathrm{~s}$ of recordings and found a significant reduction in slices from chronically VPA-treated animals $(22.7 \pm 2.1 \mathrm{~s}$ for OA; $16.3 \pm 1.3 \mathrm{~s}$ for VPA; $p<0.005$ ) (Fig. $5 C$ ). We also compared the overall time oscillations that were recorded in each slice within the first $250 \mathrm{~s}$ of recordings. This percentage of time oscillating was slightly reduced in slices from VPA-treated animals, but not to the level of statistical significance (OA, $34 \pm 7 \%$; VPA, $25 \pm 3 \%$; $p>0.05$ ) (Fig. 5D). Chronic VPA treatment thus affected several aspects of spontaneous oscillations by increasing the bursting frequency within an oscillation, as well as decreasing oscillation synchrony and the duration of oscillations.

\section{Chronic VPA treatment potentiates the effect of NPY on evoked oscillations}

The $\mathrm{Y}_{1}$ receptor blocker BIBP3226 causes network disinhibition in the thalamus (Sun et al., 2003b). Figure 6 shows example traces (A1) of a representative evoked oscillations from a chronically VPA-treated P14 animal before, during, and after BIBP3226 superfusion. Data from all traces of the recording were summarized in a contour plot (Fig. 6A2) where the $x$-axis represents time within each oscillation, the $y$-axis represents the time course throughout the experiment (sweep by sweep), and the grayscale intensity ( $z$-axis) represents the number of spikes within $50 \mathrm{~ms}$ bins. BIBP3226 caused a reversible increase in the duration of the oscillations. Figure $6 A 3$ shows autocorrelograms quantifying the increase in oscillatory decay constant in response to BIBP3226 superfusion. To quantify the effect of BIBP3226 on oscillations in 

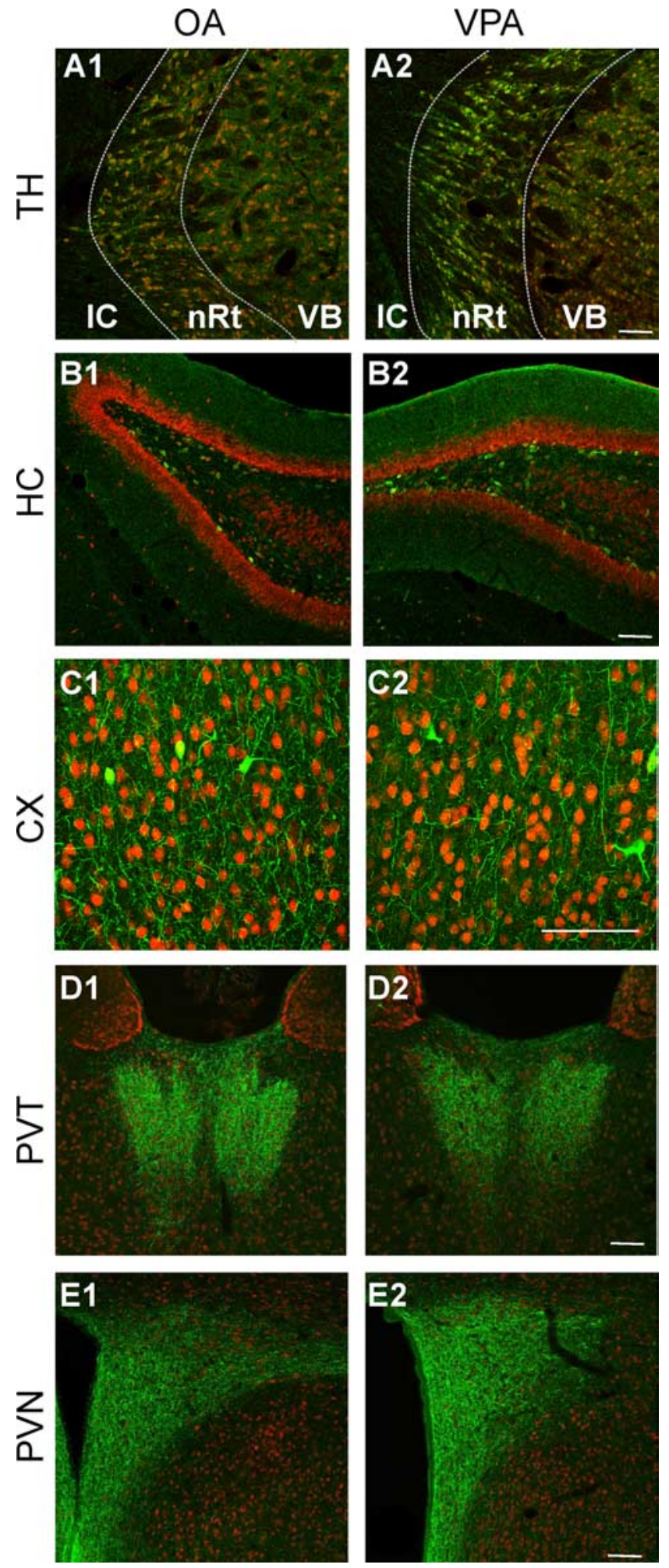

Figure 3. Immunohistochemistry: NPY expression screening in different brain regions and effects of VPA. NPY protein expression after $4 \mathrm{~d}$ of chronic OA (left panels) or VPA (right panels) in P24 male littermates. Representative images from $40 \mu \mathrm{m}$ coronal sections. Tissue was processed in parallel at all steps to allow semiquantitative comparison of NeuN and NPY immunoreactivity. Colabeling of NeuN (red immunofluorescence) and NPY (green immunofluorescence) in various brain regions of animals chronically treated with $0 A(A 1, B 1, C 1, D 1, E 1)$ or VPA $(A 2, B 2, C 2, D 2, E 2)$. $A$, Thalamus (TH), ventrobasal complex (VB) (right), nRt (center), internal capsule (IC) (left); borders are indicated by gray dotted lines. Note increased NPY immunofluorescence in $n R t$ in $\mathbf{A 2}$. B , Dentate gyrus/hilus (HC). Note increased NPY expression in dentate gyrus in B2, mainly in processes in the molecular layer and in somatodendritic compartments of hilar interneurons. C, Primary somatosensory cortex, middle layers (CX). D, PVT. E, PVN. Scale bar, $100 \mu \mathrm{m}$. slices from OA- and VPA-treated animals (P13-P15; OA: seven animals, 17 slices; VPA: eight animals, 17 slices), we measured and compared the decay constants and amplitudes of the oscillatory and random components of the control, BIBP3226, and washout phases of each recording. When analyzing oscillation decay constants, we found a significantly larger extent of network disinhibition (i.e., oscillatory enhancement) in response to BIBP3226 superfusion in slices from chronically VPA-treated animals (OA: $5.2 \pm 1.8 \%$ increase over control, $n=7$; VPA: $16.7 \pm$ $4.5 \%$ increase, $n=8 ; p<0.05$ ) (Fig. 6C1,C2). BIBP3226 also caused an increase in oscillatory strength (i.e., the peak amplitude of the autocorrelogram) (Fig. 6D1) in slices from VPA- and OAtreated animals. In our sample, the increase was higher in VPAtreated animals, but this trend was not statistically significant (OA: $17.3 \pm 7.3 \%$ increase over control, $n=7$; VPA: $28.2 \pm 4.7 \%$ increase, $n=7 ; p>0.05$ ) (Fig. 6D2). The extent of random spiking during these recordings was found to be highly variable and unrelated to the type of chronic treatment. The period of the oscillation was reduced in slices from VPA-treated animals, similar to what had been observed in spontaneously oscillating slice preparations (OA: $315 \pm 13 \mathrm{~ms}, n=7$; VPA: $272 \pm 11 \mathrm{~ms}, n=7$; $p<0.05)$. However, BIBP3226 did not significantly affect the period of the oscillation. These results are summarized in Table 3 .

\section{BIBP3226 does not modulate thalamic oscillations through NPFF receptors}

It has been reported that BIBP3226 also acts as an antagonist at NPFF receptors and that those receptors, among other brain regions, are expressed in nRt (Bonini et al., 2000; Mollereau et al., 2001). To ensure that the effect of BIBP3226 was mediated by $Y_{1}$ receptor and not NPFF receptor blockade, we assessed whether NPFF had an effect on oscillations in thalamic slices. At a saturating concentration of $2 \mu \mathrm{M}$, exogenously applied NPFF had no detectable effect on the duration, amplitude, and period of evoked oscillations $(n=4)$ (Table 4$)$. Thus, NPFF receptor antagonism is unlikely to contribute to the potentiation of the BIBP3226-mediated disinhibition of thalamic oscillatory activity observed in chronically VPA-treated rats.

\section{Acute VPA treatment does not affect evoked oscillations}

Because we were interested in the chronic effects of VPA treatment, we needed to assess any potential acute effects of VPA still present in the slices. Although slices had been in a holding chamber for at least an hour before recordings and were continually superfused with fresh ACSF during recordings, VPA likely remained bound to proteins or the cell membrane. We superfused slices from naive animals with VPA for up to $25 \mathrm{~min}$ and detected no reproducible alterations in the duration or amplitude of evoked oscillations at VPA concentrations of up to $1 \mathrm{~mm}$ (Fig. 6B1-B3), which likely exceeds VPA concentrations resulting from chronic treatment in vivo (Henriksen and Johannessen, 1982). The effects of acute VPA on thalamic oscillations thus appear to be insignificant in our slice preparation.

\section{Discussion}

We wanted to test the hypothesis that chronic VPA treatment leads to increased NPY expression in vivo and constitutes an antiepileptic action of VPA. The results presented here show that chronic but not acute VPA treatment resulted in increased NPY expression in a subset of the brain regions examined. Specifically, NPY was upregulated in nRt and hippocampus, but not in neocortex, suggesting that VPA influences NPY mRNA transcription 
and protein expression but not to an equal extent in all brain regions.

What might lead to the specific upregulation in nRt and hippocampus? One possibility is that longer VPA treatment than the $4 \mathrm{~d}$ used in this study might result in upregulation of NPY in other brain regions as well. Another is that the effects of VPA on NPY expression requires a concomitant increase in neuronal activity, which by itself affects NPY expression in rat cortical interneurons (Wirth et al., 1998). Alternatively, VPA might accumulate in different brain regions at different rates (Wieser, 1991). The dependence on chronic treatment suggests a time course in the order of hours/days, consistent with the time courses of VPA-mediated transcriptional changes in tissue culture (Chen et al., 1999) and in vivo (Hao et al., 2004).

VPA appears to affect NPY transcription in a specific manner, because we did not observe transcriptional changes in a number of other neuropeptides (SST, VIP, CCK) that have been shown to modulate thalamic oscillations (Cox et al., 1997; Sun et al., 2003a). We did not observe changes in $Y_{1}$ receptor mRNA. $Y_{1}$ receptor downregulation has been shown to accompany NPY upregulation in a number of studies in human and rat CNS (Kopp et al., 1999; Furtinger et al., 2001), although none of these studies involved the nRt. $Y_{1}$ receptor downregulation could offset or obscure the effects of increased NPY expression. However, in our model system, this does not appear to be the case.

Using immunohistochemical codetection of NPY and the neuronal marker protein NeuN, we found that virtually all neurons in nRt express NPY, with the majority of immunoreactivity found in the cell bodies, but also in dendritic/axonal staining and punctate staining outside cell bodies or processes, possibly representing synaptically localized NPY. Consistent with our qRT-PCR and radioimmunoassay results, NPY immunoreactivity was elevated in chronically, but not acutely, VPA-treated animals compared with OA controls. We observed similar increases in NPY expression in paired comparisons with OA, saline, and sham controls (data not shown), indicating that our pharmacologically inactive control, OA (Löscher and Nau, 1985), does not itself influence NPY expression. We detected similar increases in NPY expression in animals aged P15-P47, indicating that these effects of VPA in nRt are not limited to a specific developmental stage.

VPA influences a multitude of cellular signaling cascades causing wide-ranging changes in gene expression. VPA inhibits histone deacetylase, thereby promoting expression of genes containing REST-1 promoter elements, leading, for example, to the induction of the wnt pathway (Phiel et al., 2001; Ren et al., 2004). Independently from that, VPA induces the erk pathway leading to BDNF-mediated TrkB activation (Einat et al., 2003; Hao et al., 2004). Separate studies have shown that TrkB activation causes increased transcription of NPY mRNA in cultured cortical neu- rons (Nawa et al., 1993; Barnea et al., 2004). A recent preliminary report using cultured neuroblastoma cells indeed shows a cascade from VPA-mediated erk pathway induction to BDNF-mediated TrkB activation and NPY expression (Nadi et al., 2005).

NPY undergoes a sequence of steps in its maturation process, including proteolytic cleavage, removal of the C-terminal residue, and C-terminal amidation (Silva et al., 2002). The intermediates in NPY biosynthesis are likely also detected by the immunological assays used in this study. We therefore wanted to investigate whether NPY mRNA and protein upregulation results in a functional increase in NPY signaling.

To assess a potential effect of increased NPY signaling on thalamic oscillations, we first established what effects chronic and acute VPA treatment itself had on thalamic oscillations. VPA treatment was found to be associated with several alterations in spontaneous thalamic bursting. The intraoscillation burst frequency was increased significantly and consistently in every pair of animals analyzed. Factors affecting bursting frequency include $\mathrm{H}$ current magnitude (Luthi and McCormick, 1998) and relative contributions of $\mathrm{GABA}_{\mathrm{A}}$ and $\mathrm{GABA}_{\mathrm{B}}$ receptors to relay neuron inhibition (Huguenard, 1999). In our preparation, $G_{A B A_{A}}$ receptors were blocked; thus a shift in dependence from $\mathrm{GABA}_{\mathrm{A}}$ to 

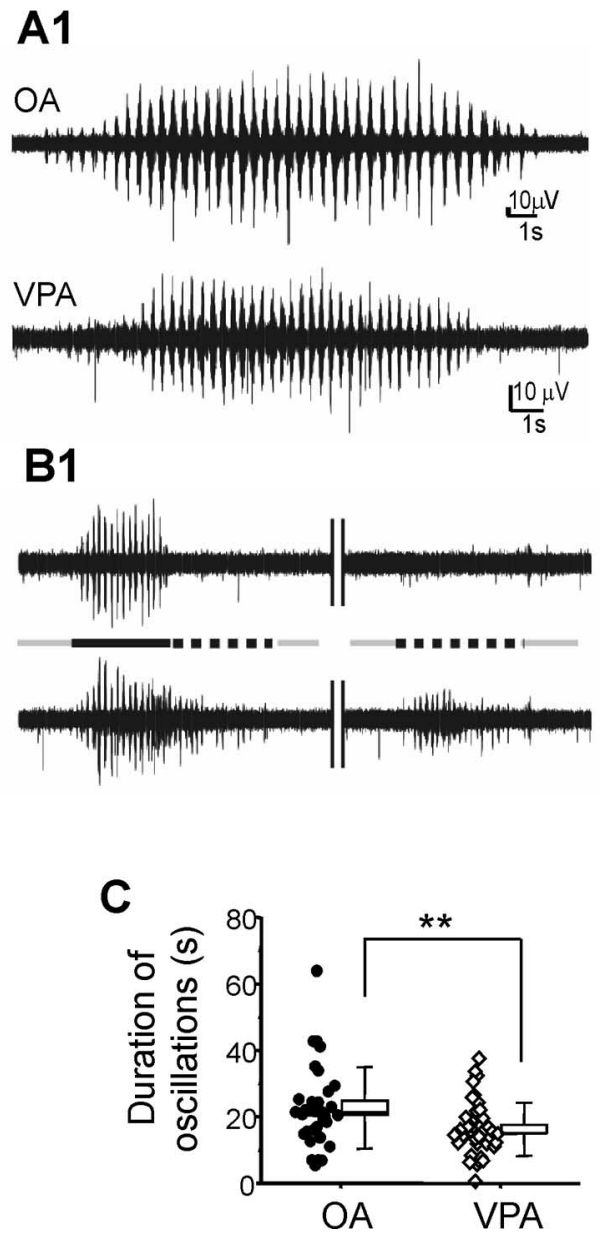

A2

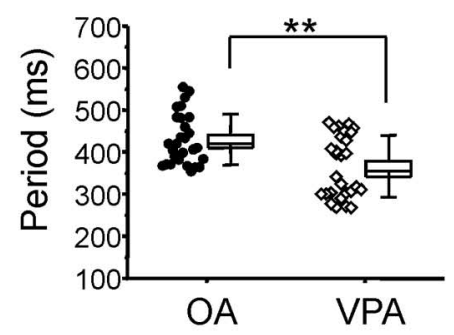

B2

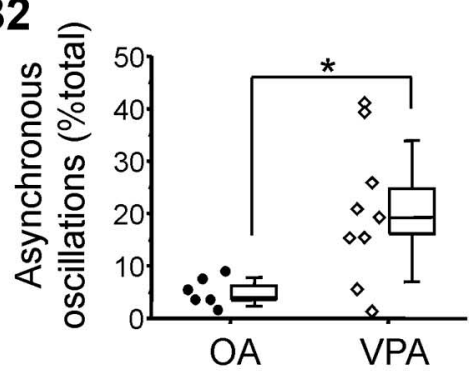

D

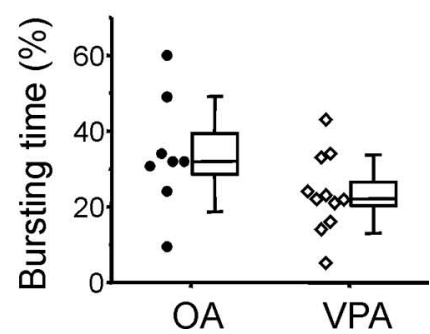

Figure 5. Effect of chronic VPA treatment on spontaneous thalamic oscillations. Oscillations were recorded using two electrodes spaced $\sim 0.5 \mathrm{~mm}$ apart in $\mathrm{nRt}$. A1, Representative traces showing oscillations in slices from 0A-(top) and VPA- (bottom) treated P14 animals (0A: 3 animals, 6 slices; VPA: 4 animals, 9 slices). A2, Bursting frequency measured in all oscillations lasting longer than $5 \mathrm{~s}$. Comparison between oscillation periods in slices from OA (solid circles) and VPA (open diamonds) animals. B1, Example of synchronous and asynchronous oscillations in simultaneous recordings. The central gray line indicates times when no rhythmic bursting was recorded with either electrode, the solid black line when rhythmic bursting was recorded with both electrodes, and the dotted black line when rhythmic bursting was recorded with only one electrode. $\boldsymbol{B 2}$, Oscillation asynchrony in each slice. Time that bursting was recorded with only one electrode as the fraction of total time bursting was recorded. Solid circles, OA; open diamonds, VPA. C, Duration of oscillations recorded in slices from OA- (black circles) and VPA- (open diamonds) treated animals. $\boldsymbol{D}$, Time that oscillations were recorded in each slice as the fraction of total time of recording. Solid circles, $0 A$; open diamonds, VPA. A2, B2, C, D, Vertical line to right of data, median; box, SE; error bars, SD. The asterisks denote significantly different average values $(p<0.01)$.

$\mathrm{GABA}_{\mathrm{B}}$ receptors is unlikely to be involved. Other potential factors could be briefer excitation of relay neurons through $\mathrm{Y}_{2}$ receptor-mediated inhibition of presynaptic calcium channels (Sun et al., 2001b) or perhaps altered neurotransmitter reuptake. The average duration of oscillations was reduced in slices from VPA-treated animals, suggesting a general decrease in neuronal excitability. Again, a number of presynaptic and postsynaptic mechanisms could be responsible, as well as alterations in neurotransmitter transporter activity. Oscillation synchrony was reduced with chronic VPA treatment, indicating that fewer neurons were recruited into oscillations under these conditions. It is unclear to what extent oscillation asynchrony is an artifact of slice preparation, but it can nevertheless be viewed as a measure of overall network excitability. These three parameters (oscillation duration, asynchony, and period) could potentially be affected by only one or by several underlying mechanisms, as will be discussed below.
Acutely applied VPA has been reported to block the paroxysmal depolarizing shift (PDS) in hippocampal CA3 neurons (Griffith and Taylor, 1988), to reduce both duration and frequency of spontaneous synchronized bursting in hippocampal CA1 and CA3 areas (Arias and Bowlby, 2005) and to inhibit the NMDAdependent PDS in amygdalar slices (Gean et al., 1994). Additionally, VPA has acute effects clinically, such as stopping status epilepticus (Sirven and Waterhouse, 2003). Acute VPA treatment, even at high concentrations, however, had no obvious effect on the oscillation parameters examined in this study. Acutely applied VPA thus likely modulates neuronal excitability via physiological targets that do not play a significant role in thalamic oscillations, affecting neither bursting frequency, amplitude, nor duration of evoked thalamic oscillations.

Absence seizures, detected by EEG in vivo in GAERS (genetic absence epilepsy rats of Strasbourg) rats, are inhibited by NPY (Stroud et al., 2005). In thalamic slice preparations, exogenous NPY inhibits thalamic oscillations, whereas application of the $\mathrm{Y}_{1}$ receptor inhibitor BIBP3226 had the opposite effect (Sun et al., 2003b). The BIBP3226-dependent enhancement of thalamic oscillations was observed in the absence of exogenous NPY, indicating that NPY is released endogenously and has a measurable effect on synchronized neuronal activity (Sun et al., 2003b). We thus hypothesize that an increase in active, releasable NPY can be detected indirectly by a potentiation of the effect of BIBP3226. Indeed, the oscillation decay constant, representative of oscillation duration, was increased after $\mathrm{Y}_{1}$ receptor blockade. The degree of BIBP3226-mediated network disinhibition was significantly larger in chronically VPA-treated animals, showing in fact an increase in mature NPY with VPA treatment. However, BIBP3226 had little or no effect on oscillation frequency, suggesting that NPY acting via $\mathrm{Y}_{1}$ receptor activity does not contribute to the increased frequency observed in slices from VPA-treated animals. Future studies could attempt to elucidate whether NPY acting through other Y receptors is responsible for the observed alteration of bursting frequency with chronic VPA treatment, or whether this constitutes an entirely separate mechanism of action.

Neurons within the nRt play a central role in the propagation of thalamic oscillations through feedback inhibition of thalamocortical relay neurons. There, hyperpolarization causes a rebound burst firing through de-inactivation of low-threshold calcium channels, leading to reexcitation of nRt neurons (Huguenard, 1999). Because relay neurons do not express measurable amounts of NPY, but both nRt and relay neurons express $\mathrm{Y}_{1}$ receptors, $\mathrm{nRt}$ neurons may form NPYergic terminals onto relay neurons as well as onto each other. Within the thalamus, 


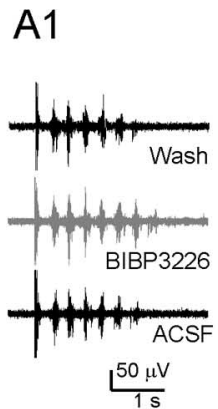

B1

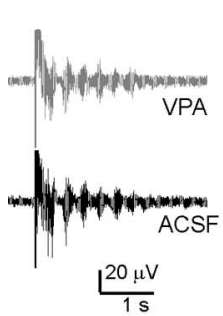

A2

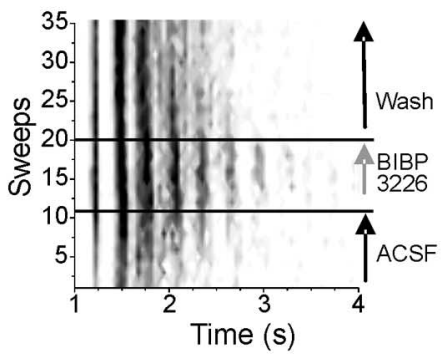

B2

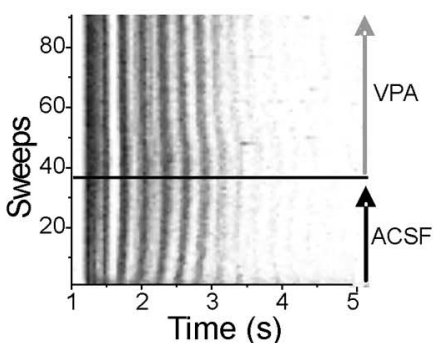

A3

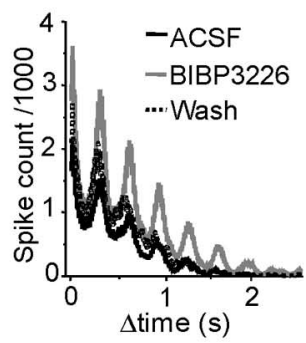

B3

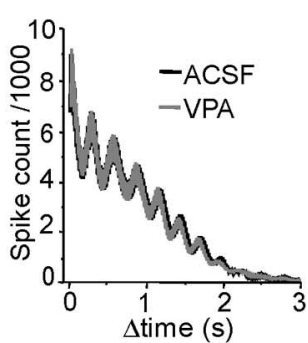

C1

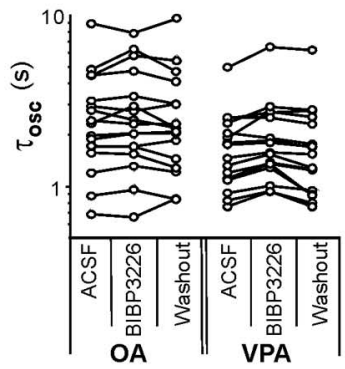

D1

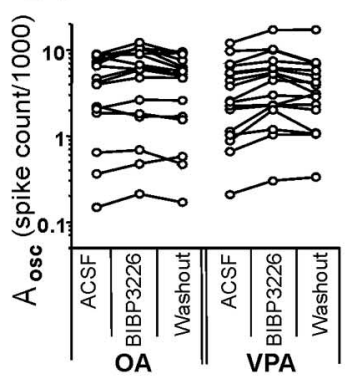

C2

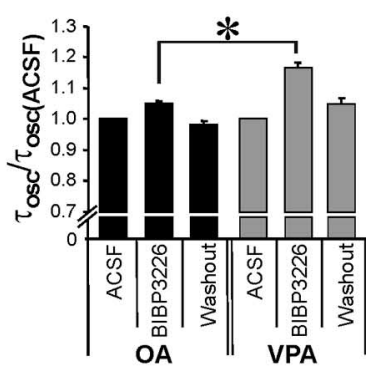

D2

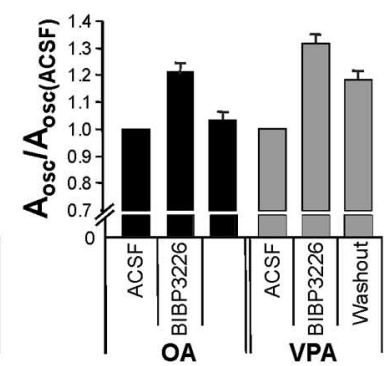

Figure 6. Effect of BIBP3226 and acutely applied VPA on evoked thalamic oscillations. $\boldsymbol{A} 1-\boldsymbol{B} 3$, Representative multiunit recordings (A1, $\boldsymbol{B 1})$, contour plots $(\boldsymbol{A 2}, \boldsymbol{B 2})$, and autocorrelograms (A3, $B 3$ ) showing effects of BIBP3226 (A1-A3) or acutely applied VPA (B1-B3) on thalamic oscillations in nRt. Traces in $A 1$ and $B 1$ show oscillatory burst responses to single extracellular stimuli in control solution and during test compound superfusion. The top trace in $\boldsymbol{A} \mathbf{1}$ shows bursting during BIBP3226 washout. The contour plots $(\boldsymbol{A 2}, \mathbf{B 2})$ represent rate meter of extracellularly recorded spikes. The $x$-axis represents time within each evoked oscillation, and the $y$-axis represents the time course throughout the experiment indicated as number of sweeps, which were recorded every $35 \mathrm{~s}$. The $z$-axis represents the spike intensity during single evoked oscillations; darker grayscale levels correspond to higher numbers of spikes within $50 \mathrm{~ms}$ bins. The arrows on the right indicate times of superfusion with control solution and test compounds; the black triangle indicates the time of stimulus. Autocorrelograms in $\boldsymbol{A} \mathbf{3}$ and $\boldsymbol{B} 3$ show overall oscillatory activity for control (black line), test compound application (gray line), and wash (black dotted line). C1, Oscillation decay constants in slices from OA- and VPA-treated animals under control conditions (ACSF), during superfusion of $1 \mu \mathrm{M}$ BIBP3226, and during washout. C2, Summarized data; decay constants in each slice were normalized to control conditions. Black bars, OA; gray bars, VPA. The asterisk denotes

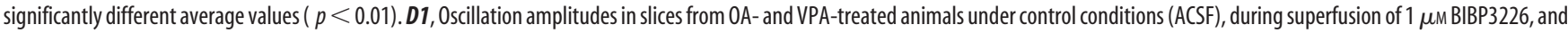
during washout. D2, Summarized data; amplitudes in each slice were normalized to control conditions. Black bars, OA; gray bars, VPA. Error bars indicate SEM.

Table 3. Effect of BIBP3226 in slices (one to four per animal) from chronically OA- $(n=7)$ or VPA- $(n=8)$ treated P13-P15 animals

\begin{tabular}{|c|c|c|c|c|c|c|}
\hline & \multicolumn{3}{|l|}{$O A$} & \multicolumn{3}{|l|}{ VPA } \\
\hline & ACSF & BIBP3226 & Washout & ACSF & BIBP3226 & Washout \\
\hline Oscillation amplitude & $5246 \pm 1001$ & $6262 \pm 1399$ & $5053 \pm 986$ & $\begin{array}{l}3209 \pm 943 \\
p<0.5\end{array}$ & $4222 \pm 1253$ & $3806 \pm 1117$ \\
\hline Normalized & 1 & $1.17 \pm 0.07$ & $0.98 \pm 0.06$ & 1 & $\begin{array}{l}1.28 \pm 0.05 \\
p<0.5\end{array}$ & $1.16 \pm 0.09$ \\
\hline$\tau$ Oscillation & $2889 \pm 576$ & $3046 \pm 587$ & $2839 \pm 584$ & $\begin{array}{l}1839 \pm 315 \\
p<0.5\end{array}$ & $2157 \pm 398$ & $1986 \pm 405$ \\
\hline Normalized & 1 & $1.05 \pm 0.02$ & $0.98 \pm 0.03$ & 1 & $\begin{array}{l}1.17 \pm 0.05 \\
p<0.05^{*}\end{array}$ & $1.05 \pm 0.05$ \\
\hline Oscillation period (ms) & $315 \pm 13$ & $319 \pm 13$ & $326 \pm 14$ & $\begin{array}{c}272 \pm 11 \\
p<0.05^{*}\end{array}$ & $276 \pm 10$ & $280 \pm 10$ \\
\hline Nonoscillatory amplitude & $1614 \pm 536$ & $1673 \pm 611$ & $1332 \pm 532$ & $\begin{array}{l}1474 \pm 474 \\
p>0.5\end{array}$ & $1736 \pm 511$ & $1363 \pm 397$ \\
\hline Normalized & 1 & $1.00 \pm 0.12$ & $0.79 \pm 0.14$ & 1 & $\begin{array}{l}1.22 \pm 0.12 \\
p<0.05^{*}\end{array}$ & $1.05 \pm 0.15$ \\
\hline$\tau$ Nonoscillatory & $6846 \pm 2624$ & $4217 \pm 1376$ & $3674 \pm 1442$ & $\begin{array}{l}2130 \pm 403 \\
p<0.5\end{array}$ & $1984 \pm 494$ & $1714 \pm 185$ \\
\hline Normalized & 1 & $0.86 \pm 0.08$ & $0.80 \pm 0.11$ & 1 & $\begin{array}{l}0.93 \pm 0.08 \\
p>0.5\end{array}$ & $0.82 \pm 0.09$ \\
\hline
\end{tabular}

Parameters for evoked oscillations in nRt according to the equation given in Materials and Methods. To identify changes caused by VPA treatment alone, comparisons were made between raw data in control conditions (ACSF) for slices from OA- and VPA-treated animals. To assess differential effects of VPA treatment on NPY signaling, comparisons were made between normalized data during BIBP3226 superfusion (Y, receptor blockade) in slices from OA- and VPA-treated animals. The asterisks denote statistical significance in comparisons between OA and VPA, either in baseline parameters (see column VPA/ACSF for raw data) or in degree of change upon BIBP3226 appplication (see column VPA/BIBP3226 for normalized data).

NPY activates postsynaptic inwardly rectifying potassium channels through $Y_{1}$ receptors, whereas $Y_{2}$ receptor activation inhibits presynaptic calcium channels (Sun et al., 2001a,b). Increased NPY released from nRt could thus cause hyperpolarization in other nRt neurons, reducing the number of action potentials fired, the extent of subsequent relay neuron hyperpolarization, leading to less complete T-type calcium channel de-inactivation and a smaller rebound burst. 
Table 4. Effect of NPFF in slices $(n=4)$ from a naive P14 animal

\begin{tabular}{llcc}
\hline & ACSF & NPFF & Washout \\
\hline Oscillation amplitude & $5925 \pm 2864$ & $6348 \pm 3424$ & $6368 \pm 3852$ \\
Normalized & 1 & $1.01 \pm 0.13$ & $1.04 \pm 0.02$ \\
$\tau$ Oscillation & $3405 \pm 1384$ & $3667 \pm 1615$ & $4126 \pm 2037$ \\
Normalized & 1 & $1.07 \pm 0.03$ & $1.18 \pm 0.15$ \\
Oscillation period & $346 \pm 50$ & $343 \pm 34$ & $346 \pm 32$ \\
Normalized & 1 & $1.00 \pm 0.07$ & $1.01 \pm 0.07$ \\
\hline
\end{tabular}

Parameters for evoked oscillations in nRt according to the equation given in Materials and Methods. The table lists raw and normalized data for oscillation amplitude, oscillation decay constant, and bursting period. NPFF application did not cause statistically significant changes in these parameters $(p>0.1)$.

VPA is used in the management of absence as well as complex partial seizures (temporal lobe epilepsy) (Willmore, 2003), suggesting that specific NPY upregulation in the nRt and dentate gyrus, regions involved in the propagation of absence and temporal lobe seizures, respectively, may indeed constitute one of its clinical mechanisms of action.

\section{References}

Arias RL, Bowlby MR (2005) Pharmacological characterization of antiepileptic drugs and experimental analgesics on low magnesium-induced hyperexcitability in rat hippocampal slices. Brain Res 1047:233-244.

Asghari V, Wang JF, Reiach JS, Young LT (1998) Differential effects of mood stabilizers on Fos/Jun proteins and AP-1 DNA binding activity in human neuroblastoma SH-SY5Y cells. Brain Res Mol Brain Res 58:95-102.

Barnea A, Roberts J, Croll SD (2004) Continuous exposure to brain-derived neurotrophic factor is required for persistent activation of TrkB receptor, the ERK signaling pathway, and the induction of neuropeptide $Y$ production in cortical cultures. Brain Res 1020:106-117.

Bonini JA, Jones KA, Adham N, Forray C, Artymyshyn R, Durkin MM, Smith KE, Tamm JA, Boteju LW, Lakhlani PP, Raddatz R, Yao WJ, Ogozalek KL, Boyle N, Kouranova EV, Quan Y, Vaysse PJ, Wetzel JM, Branchek TA, Gerald C, Borowsky B (2000) Identification and characterization of two $\mathrm{G}$ protein-coupled receptors for neuropeptide FF. J Biol Chem 275:39324-39331.

Bourgeois B, Beaumanoir A, Blajev B, de la Cruz N, Despland PA, Egli M, Geudelin B, Kaspar U, Ketz E, Kronauer C (1987) Monotherapy with valproate in primary generalized epilepsies. Epilepsia 28 [Suppl 2]:S8-S11.

Burr W, Froescher W, Hoffmann F, Stefan H (1984) Lack of significant correlation between circadian profiles of valproic acid serum levels and epileptiform electroencephalographic activity. Ther Drug Monit 6:179-181.

Chadwick DW (1985) Concentration-effect relationships of valproic acid. Clin Pharmacokinet 10:155-163.

Chen G, Yuan PX, Jiang YM, Huang LD, Manji HK (1999) Valproate robustly enhances AP-1 mediated gene expression. Brain Res Mol Brain Res 64:52-58.

Chronwall BM, DiMaggio DA, Massari VJ, Pickel VM, Ruggiero DA, O'Donohue TL (1985) The anatomy of neuropeptide-Y-containing neurons in rat brain. Neuroscience 15:1159-1181.

Cox CL, Huguenard JR, Prince DA (1997) Peptidergic modulation of intrathalamic circuit activity in vitro: actions of cholecystokinin. J Neurosci $17: 70-82$.

Eckstein-Ludwig U, Fei J, Schwarz W (1999) Inhibition of uptake, steadystate currents, and transient charge movements generated by the neuronal GABA transporter by various anticonvulsant drugs. Br J Pharmacol 128:92-102.

Einat H, Yuan P, Gould TD, Li J, Du J, Zhang L, Manji HK, Chen G (2003) The role of the extracellular signal-regulated kinase signaling pathway in mood modulation. J Neurosci 23:7311-7316.

Ekstrand AJ, Cao R, Bjorndahl M, Nystrom S, Jonsson-Rylander AC, Hassani H, Hallberg B, Nordlander M, Cao Y (2003) Deletion of neuropeptide Y (NPY) 2 receptor in mice results in blockage of NPY-induced angiogenesis and delayed wound healing. Proc Natl Acad Sci USA 100:6033-6038.

Erickson JC, Clegg KE, Palmiter RD (1996) Sensitivity to leptin and susceptibility to seizures of mice lacking neuropeptide Y. Nature 381:415-418.

Eyer F, Felgenhauer N, Gempel K, Steimer W, Gerbitz KD, Zilker T (2005)
Acute valproate poisoning: pharmacokinetics, alteration in fatty acid metabolism, and changes during therapy. J Clin Psychopharmacol $25: 376-380$.

Fraser CM, Sills GJ, Butler E, Thompson GG, Lindsay K, Duncan R, Howatson A, Brodie MJ (1999) Effects of valproate, vigabatrin and tiagabine on GABA uptake into human astrocytes cultured from foetal and adult brain tissue. Epileptic Disord 1:153-157.

Furtinger S, Pirker S, Czech T, Baumgartner C, Ransmayr G, Sperk G (2001) Plasticity of $\mathrm{Y} 1$ and $\mathrm{Y} 2$ receptors and neuropeptide $\mathrm{Y}$ fibers in patients with temporal lobe epilepsy. J Neurosci 21:5804-5812.

Gean PW, Huang CC, Hung CR, Tsai JJ (1994) Valproic acid suppresses the synaptic response mediated by the NMDA receptors in rat amygdalar slices. Brain Res Bull 33:333-336.

Griffith WH, Taylor L (1988) Sodium valproate decreases synaptic potentiation and epileptiform activity in hippocampus. Brain Res 474:155-164.

Hansel DE, Eipper BA, Ronnett GV (2001) Neuropeptide Y functions as a neuroproliferative factor. Nature 410:940-944.

Hao Y, Creson T, Zhang L, Li P, Du F, Yuan P, Gould TD, Manji HK, Chen G (2004) Mood stabilizer valproate promotes ERK pathway-dependent cortical neuronal growth and neurogenesis. J Neurosci 24:6590-6599.

Hassel B, Iversen EG, Gjerstad L, Tauboll E (2001) Up-regulation of hippocampal glutamate transport during chronic treatment with sodium valproate. J Neurochem 77:1285-1292.

Henriksen O, Johannessen SI (1982) Clinical and pharmacokinetic observations on sodium valproate-a 5-year follow-up study in 100 children with epilepsy. Acta Neurol Scand 65:504-523.

Huguenard JR (1999) Neuronal circuitry of thalamocortical epilepsy and mechanisms of anti-absence drug action. In: Basic mechanisms of the epilepsies (Delgado-Escueta AV, Wilson WA, Olsen RW, Porter RJ, eds), pp 991-999. New York: Lippincott-Raven.

Huguenard JR, Prince DA (1994) Intrathalamic rhythmicity studied in vitro: nominal $\mathrm{T}$ current modulation causes robust anti-oscillatory effects. J Neurosci 14:5485-5502.

Jacobsen RB, Ulrich D, Huguenard JR (2001) GABA $_{B}$ and NMDA receptors contribute to spindle-like oscillations in rat thalamus in vitro. J Neurophysiol 86:1365-1375.

Kopp J, Nanobashvili A, Kokaia Z, Lindvall O, Hokfelt T (1999) Differential regulation of mRNAs for neuropeptide $\mathrm{Y}$ and its receptor subtypes in widespread areas of the rat limbic system during kindling epileptogenesis. Brain Res Mol Brain Res 72:17-29.

Kraiczi H, Karlsson G, Ekman R (1997) Analytical extraction of regulatory peptides from rat lung tissue. Peptides 18:1597-1601.

Löscher W (1999) Valproate: a reappraisal of its pharmacodynamic properties and mechanisms of action. Prog Neurobiol 58:31-59.

Löscher W, Honack D (1995) Comparison of anticonvulsant efficacy of valproate during prolonged treatment with one and three daily doses or continuous ("controlled release") administration in a model of generalized seizures in rats. Epilepsia 36:929-937.

Löscher W, Nau H (1985) Pharmacological evaluation of various metabolites and analogues of valproic acid. Anticonvulsant and toxic potencies in mice. Neuropharmacology 24:427-435.

Luthi A, McCormick DA (1998) H-current: properties of a neuronal and network pacemaker. Neuron 21:9-12.

Marksteiner J, Lassmann H, Saria A, Humpel C, Meyer DK, Sperk G (1990) Neuropeptide levels after pentylenetetrazol kindling in the rat. Eur J Neurosci 2:98-103.

Meeren HK, Pijn JP, Van Luijtelaar EL, Coenen AM, Lopes da Silva FH (2002) Cortical focus drives widespread corticothalamic networks during spontaneous absence seizures in rats. J Neurosci 22:1480-1495.

Mollereau C, Gouarderes C, Dumont Y, Kotani M, Detheux M, Doods H, Parmentier M, Quirion R, Zajac JM (2001) Agonist and antagonist activities on human $\operatorname{NPFF}(2)$ receptors of the NPY ligands GR231118 and BIBP3226. Br J Pharmacol 133:1-4.

Morland C, Boldingh KA, Iversen EG, Hassel B (2004) Valproate is neuroprotective against malonate toxicity in rat striatum: an association with augmentation of high-affinity glutamate uptake. J Cereb Blood Flow Metab 24:1226-1234.

Nadi N, Chen T, Sweet M (2005) Neuropeptide Y may be the final common pathway of valproic acid. Soc Neurosci Abstr 31:94.9.

Nadi NS, Swiergosz MJ, Khalid K (1999) Neuropeptide Y inhibits oxygeninduced seizures through the Y2-Y5 receptor. Soc Neurosci Abstr $25: 544.3$ 
Nawa H, Bessho Y, Carnahan J, Nakanishi S, Mizuno K (1993) Regulation of neuropeptide expression in cultured cerebral cortical neurons by brain-derived neurotrophic factor. J Neurochem 60:772-775.

Phiel CJ, Zhang F, Huang EY, Guenther MG, Lazar MA, Klein PS (2001) Histone deacetylase is a direct target of valproic acid, a potent anticonvulsant, mood stabilizer, and teratogen. J Biol Chem 276:36734-36741.

Reibel S, Larmet Y, Carnahan J, Marescaux C, Depaulis A (2000) Endogenous control of hippocampal epileptogenesis: a molecular cascade involving brain-derived neurotrophic factor and neuropeptide Y. Epilepsia 41 [Suppl 6]:S127-S133.

Ren M, Leng Y, Jeong M, Leeds PR, Chuang DM (2004) Valproic acid reduces brain damage induced by transient focal cerebral ischemia in rats: potential roles of histone deacetylase inhibition and heat shock protein induction. J Neurochem 89:1358-1367.

Rowan AJ, Binnie CD, Warfield CA, Meinardi H, Meijer JW (1979) The delayed effect of sodium valproate on the photoconvulsive response in man. Epilepsia 20:61-68.

Silva AP, Cavadas C, Grouzmann E (2002) Neuropeptide Y and its receptors as potential therapeutic drug targets. Clin Chim Acta 326:3-25.

Sirven JI, Waterhouse E (2003) Management of status epilepticus. Am Fam Physician 68:469-476.

Stroud LM, O'Brien TJ, Jupp B, Wallengren C, Morris MJ (2005) Neuropeptide $\mathrm{Y}$ suppresses absence seizures in a genetic rat model. Brain Res 1033:151-156.

Sun QQ, Huguenard JR, Prince DA (2001a) Neuropeptide Y receptors differentially modulate $\mathrm{G}$-protein-activated inwardly rectifying $\mathrm{K}^{+}$channels and high-voltage-activated $\mathrm{Ca}^{2+}$ channels in rat thalamic neurons. J Physiol (Lond) 531:67-79.

Sun QQ, Akk G, Huguenard JR, Prince DA (2001b) Differential regulation of GABA release and neuronal excitability mediated by neuropeptide Y1 and Y2 receptors in rat thalamic neurons. J Physiol (Lond) 531:81-94.

Sun QQ, Huguenard JR, Prince DA (2002) Somatostatin inhibits thalamic network oscillations in vitro: actions on the GABAergic neurons of the reticular nucleus. J Neurosci 22:5374-5386.

Sun QQ, Prince DA, Huguenard JR (2003a) Vasoactive intestinal polypeptide and pituitary adenylate cyclase-activating polypeptide activate hyper- polarization activated cationic current and depolarize thalamocortical neurons in vitro. J Neurosci 23:2751-2758.

Sun QQ, Baraban SC, Prince DA, Huguenard JR (2003b) Target-specific neuropeptide Y-ergic synaptic inhibition and its network consequences within the mammalian thalamus. J Neurosci 23:9639-9649.

Sundqvist A, Tomson T, Lundkvist B (1998) Valproate as monotherapy for juvenile myoclonic epilepsy: dose-effect study. Ther Drug Monit 20:149-157.

Tabb K, Szot P, White SS, Liles LC, Weinshenker D (2004) The ketogenic diet does not alter brain expression of orexigenic neuropeptides. Epilepsy Res 62:35-39.

Tu B, Timofeeva O, Jiao Y, Nadler JV (2005) Spontaneous release of neuropeptide $Y$ tonically inhibits recurrent mossy fiber synaptic transmission in epileptic brain. J Neurosci 25:1718-1729.

Ueda Y, Willmore LJ (2000) Molecular regulation of glutamate and GABA transporter proteins by valproic acid in rat hippocampus during epileptogenesis. Exp Brain Res 133:334-339.

Vezzani A, Sperk G (2004) Overexpression of NPY and Y2 receptors in epileptic brain tissue: an endogenous neuroprotective mechanism in temporal lobe epilepsy? Neuropeptides 38:245-252.

Vezzani A, Sperk G, Colmers WF (1999) Neuropeptide Y: emerging evidence for a functional role in Seizure modulation. Trends Neurosci 22:25-30.

Whitlow RD, Sacher A, Loo DD, Nelson N, Eskandari S (2003) The anticonvulsant valproate increases the turnover rate of $\gamma$-aminobutyric acid transporters. J Biol Chem 278:17716-17726.

Wieser HG (1991) Comparison of valproate concentrations in human plasma, CSF and brain tissue after administration of different formulations of valproate or valpromide. Epilepsy Res 9:154-159.

Willmore LJ (2003) Divalproex and epilepsy. Psychopharmacol Bull 37 [Suppl 2]:43-53.

Wirth MJ, Gorba T, Wahle P (1998) Epigenetic factors regulate the NPY expression in rat cortical neurons. Regul Pept 75-76:283-292.

Zhao S, Fernald RD (2005) Comprehensive algorithm for quantitative realtime polymerase chain reaction. J Comput Biol 12:1045-1062. 